\title{
Impact of "non-clamping technique" on intra- and postoperative course after laparoscopic partial nephrectomy
}

\author{
Piotr Petrasz, Marcin Słojewski, Andrzej Sikorski \\ Department of Urology and Urological Oncology, Pomeranian Medical University, Szczecin, Poland
}

Videosurgery Miniinv 2012; 7 (4): 275-279

DOI: 10.5114/wiitm.2011.30801

\begin{abstract}
Introduction: The use of kidney warm ischaemia during laparoscopic partial nephrectomy (LPN) may lead to damage of renal vessels and kidney failure. Laparoscopic partial nephrectomy done without clamping the renal pedicle is feasible and may be beneficial for the postoperative course.

Aim: To compare intra- and postoperative course in patients undergoing LPN with and without kidney warm ischaemia.

Material and methods: The material comprises 38 consecutive patients, who underwent LPN in our department during the years 2008-2009. In all cases renal vessels were identified and dissected at first, then resection of the tumour was done. Warm ischaemia was used only in case of difficulties with identification of tumour margin or with the management of bleeding. Out of 38 operations 13 were done without clamping the renal pedicle (group 1) and in the remaining 25 warm ischaemia was applied (group 2).

Results: Mean dimension of resected tumours in groups 1 and 2 was $31 \mathrm{~mm}$ and $33 \mathrm{~mm}$ respectively $(p>0.05)$, while parameters of intra- and postoperative course differed significantly between the groups: mean blood loss $-135 \mathrm{ml} v \mathrm{~s}$. $354 \mathrm{ml}(p<0.05)$, time of surgery - $72.6 \mathrm{~min} v \mathrm{vs} .132 .2 \mathrm{~min}(p<0.05)$, postoperative drain leakage $-290 \mathrm{ml} \mathrm{vs.} 504 \mathrm{ml}$ $(p<0.05)$, postoperative hospital stay -3.1 days vs 5.3 days $(p<0.05)$. In all patients baseline creatinine levels were normal while after surgery creatinine elevation over the upper limit was found in groups 1 and 2 in one and in 6 patients respectively $(p<0.05)$.

Conclusions: Laparoscopic resection of kidney tumour without warm ischaemia is feasible and beneficial in pre-and intraoperatively selected cases. Bleeding from renal parenchyma, which requires renal pedicle clamping, may seriously deteriorate intra- and postoperative course in patients undergoing laparoscopic partial nephrectomy.
\end{abstract}

Key words: kidney cancer, laparoscopic partial nephrectomy, haemostasis, kidney warm ischaemia.

\section{Introduction}

Surgery as the only curative treatment of proven value in patients with renal cancer still remains the main method used for the management of kidney tumours. For a long time open radical nephrectomy was the standard of care in these patients, but in the early 1990s it was replaced with laparoscopic techniques, which can be successfully applied in most cases of T1 and T2 tumours [1]. After a few years of gaining experience with laparoscopic radical nephrectomy, this method has become recommended for the treatment of selected patients by most urological organizations [2-4]. Due to improvement of surgical techniques, indications for radical nephrectomy have evolved, and currently kidney sparing surgery is the recommended treat-

Address for correspondence:

Piotr Petrasz MD, 5 Kruczkowskiego 72-100 Goleniow, Poland, phone: +48 606240 039, fax: +48 9146611 00, e-mail: petri6977@wp.pl 
ment for small, organ-confined kidney masses [4]. The wide use of ultrasonography and computed tomography facilitates an increase of the number of incidentally detected low stage kidney tumours and prompts the development of new, less invasive, organ-sparing surgical techniques, such as laparoscopic partial nephrectomy (LPN) [5]. In the hands of a skilled laparoscopist LPN is an effective and safe procedure which allows one to replicate the techniques used in open surgery with the advantages of a minimally invasive approach [6]. Nevertheless, LPN has to be considered as probably one of the most challenging procedures in urological laparoscopy, mainly due to difficult control of bleeding from the renal parenchyma. Obtaining haemostasis is a primary concern during LPN as it influences not only patients' safety and risk of conversion to open procedure, but it may also compromise the oncological result [7]. The main techniques of bleeding management comprise the use of coagulation (mono, bipolar and argon), the use of topical haemostatic agents and kidney haemostatic suture. From the technical point of view there are three strategies for laparoscopic nephron-sparing surgery. Resection of a tumour without ischaemia is proven to be feasible in small, peripheral masses [8]. Furthermore, the tumour may be resected in a bloodless field, established either by complete renal ischaemia through clamping the renal pedicle or by local ischaemia through compressing the renal parenchyma [5, 9]. A bloodless field facilitates precise tumour resection, control of larger vessels and suture repair of the collecting system, but increases the risk of renal vessel damage and kidney insufficiency [10].

Since 2004 LPN has been routinely used in our department for the treatment of patients with T1a kidney tumours. During this time we have done over 130 LPN and in 2008 we started to perform this procedure without warm ischaemia whenever possible.

\section{Aim}

In this study we aim to analyse the intra- and postoperative course in a group of patients undergoing LPN without warm ischaemia (group 1) and in a group of patients in whom in order to obtain suitable haemostasis renal vessels had to be temporarily clamped (group 2).

\section{Material and methods}

The study material comprises 38 consecutive patients, who underwent laparoscopic partial nephrectomy between January 2008 and December 2009. Mean age of patients in group 1 and group 2 was 54.7 years (range: $29-69$ years) and 58.3 years (range: $32-77$ years) respectively $(p>0.05)$. In most cases (30 patients $-79 \%$ ) the retroperitoneal access was used with two $10 \mathrm{~mm}$ trocars and one $5 \mathrm{~mm}$ trocar. In the remaining 8 cases (21\%) we applied a transperitoneal approach due to the tumour localization. In all cases the identification and dissection of renal vessels was the first step, so they could be immediately clamped if necessary. In every case we started to excise the tumour without kidney ischaemia and the renal pedicle was closed with an intestinal clamp introduced through an additional $10 \mathrm{~mm}$ trocar only in case of excessive bleeding aggravating clear tumour resection, repair of the collecting system or performing satisfactory haemostasis of renal parenchyma. Out of 38 patients 13 (34\%) were operated on without warm ischaemia (group 1), and in the remaining $25(66 \%)$ due to bleeding the renal pedicle had to be temporarily closed (group 2). After completing tumour excision haemostasis of the lodge was done with coagulation (mono, bipolar, argon), locally acting haemostatic agents (fibrin sponge, tissue sealant) and kidney haemostatic suture according to topical indications. The tumour was removed in an endoscopic bag at the end of the operation.

Demographic, radiographic, laboratory, operative, perioperative and pathological data were recorded. Variables including tumour diameter, blood loss, time of surgery, intra- and postoperative complications, blood transfusion, hospital stay and creatinine level were analysed and compared. A clinical database of baseline, peri- and postoperative data was completed prospectively.

\section{Statistical analysis}

For statistical analysis $\chi^{2}$ and the Mann-Whitney $U$-test were applied with $p \leq 0.05$ indicating statistical significance.

\section{Results}

The mean diameter of the resected tumour did not differ statistically significantly between group 1 and group 2, and it was $31 \mathrm{~mm}$ (range: 9-65 mm) and 
Table I. Comparison of histopathological results between group 1 and group 2

\begin{tabular}{|lccc|}
\hline Variables & $\begin{array}{l}\text { Group 1 } \\
(n=13)\end{array}$ & $\begin{array}{l}\text { Group 2 } \\
(n=25)\end{array}$ & Value of $p$ \\
\hline pT1a & $11(85 \%)$ & $22(12 \%)$ & $>0.05$ \\
\hline pT1b & $2(15 \%)$ & $3(12 \%)$ & $>0.05$ \\
\hline Gl & $6(46 \%)$ & $7(28 \%)$ & $>0.05$ \\
\hline Gll & $3(23 \%)$ & $13(52 \%)$ & $>0.05$ \\
\hline GIII & $0(0 \%)$ & $1(4 \%)$ & $>0.05$ \\
\hline Benign tumours & $4(31 \%)$ & $4(16 \%)$ & $>0.05$ \\
\hline Positive surgical & $0(0 \%)$ & $1(4 \%)$ & $>0.05$ \\
margins & $13(100 \%)$ & $24(96 \%)$ & $>0.05$ \\
\hline $\begin{array}{l}\text { Negative surgical } \\
\text { margins }\end{array}$ & $7(53 \%)$ & $17(68 \%)$ & $>0.05$ \\
\hline Clear cell cancer & $1(8 \%)$ & $3(12 \%)$ & $>0.05$ \\
\hline Papillary cancer & $1(4 \%)$ & $>0.05$ \\
\hline Chromophobic cancer & $1(8 \%)$ & $1(4 \%)$ & $>0.05$ \\
\hline Oncocytoma & $1(8 \%)$ & $3(12 \%)$ & $>0.05$ \\
\hline Angiomyolipoma & $3(23 \%)$ & \\
\hline
\end{tabular}

$33 \mathrm{~mm}$ (range: 20-60 $\mathrm{mm}$ ) respectively. Histopathological results are presented in Table I; there are no significant differences between the groups. In group 1 surgical margins were assessed as negative, while in group 2 in 1 patient the result was positive.

In patients operated on due to excessive bleeding with a clamped renal pedicle advanced haemostatic techniques such as tissue sealant (Tachosil ${ }^{\circledR}$ ) and kidney suture had to be used more often in order to perform haemostasis. Mean time of warm ischaemia in group 2 was 18.4 min (range: 3-35 min). The use of methods of performing haemostasis in both groups is presented in Table II.

Statistically significant differences between the groups were found with regard to intraoperative course. In group 1 and group 2 mean time of surgery was $72.6 \mathrm{~min}$ and $132.2 \mathrm{~min}$ respectively $(p<0.05)$. Mean blood loss was $135.3 \mathrm{ml}$ (group 1) and $354 \mathrm{ml}$ (group 2) $(p<0.05)$. None of the patients from group 1 was converted to open surgery while in group 2 in 6 cases due to difficulties with performing haemostasis conversion was necessary, despite the clamped renal pedicle. Due to postoperative bleeding (2 patients) and prolonged urinary drain leakage
Table II. Comparison of techniques used for performing haemostasis after kidney tumour excision

\begin{tabular}{|lcc|}
\hline Technique & $\begin{array}{c}\text { Group 1 } \\
(n=13)\end{array}$ & $\begin{array}{c}\text { Group 2 } \\
(n=25)\end{array}$ \\
\hline Argon coagulation & 13 & 25 \\
\hline Fibrin sponge & 11 & 0 \\
\hline Tissue sealant & 0 & 5 \\
\hline Haemostatic suture & 2 & 12 \\
\hline Time of warm ischaemia [min] & 0 & $18.4(3-35)$ \\
\hline
\end{tabular}

(1 patient) altogether 3 patients in group 2 were reoperated on. In group 1 no serious postoperative complications were noted. Preoperative creatinine level was within the normal range in all studied patients $(n=38)$. Mean increase of postoperative creatinine level was significantly higher in group 2 where in 6 patients it reached abnormal values, while in group 1 postoperative creatinine level elevation exceeding the normal range was found only in 1 case. Mean volume of drain leakage was significantly lower in group 1 $(290 \mathrm{ml})$ than in group $2(504 \mathrm{ml})(p<0.05)$, as well as the number of transfused blood units, which was significantly lower in patients from group 1. Mean time of postoperative hospital stay was higher in

Table III. Comparison of postoperative course parameters between groups

\begin{tabular}{|lccc|}
\hline Variables & $\begin{array}{c}\text { Group 1 } \\
(n=13)\end{array}$ & $\begin{array}{c}\text { Group 2 } \\
(n=25)\end{array}$ & Value of $p$ \\
\hline $\begin{array}{l}\text { Creatinine }<1.2 \mathrm{mg} / \mathrm{dl} \\
\text { before LPN }\end{array}$ & $13(100 \%)$ & $25(100 \%)$ & $>0.05$ \\
\hline $\begin{array}{l}\text { Creatinine }>1.2 \mathrm{mg} / \mathrm{dl} \\
\text { after LPN }\end{array}$ & $1(7.7 \%)$ & $6(24 \%)$ & $<0.05$ \\
\hline $\begin{array}{l}\text { Mean increase of } \\
\text { creatinine level [mg/dl] }\end{array}$ & 0.099 & 0.369 & $<0.05$ \\
\hline $\begin{array}{l}\text { Mean drain leakage [ml] } \\
\text { Blood transfusion } \\
\text { (number of patients) }\end{array}$ & 290 & 504 & $<0.05$ \\
\hline $\begin{array}{l}\text { Blood transfusion } \\
\text { (number of RBU1) }\end{array}$ & 3 & 6 & $<0.05$ \\
\hline $\begin{array}{l}\text { Median hospitalization } \\
\text { after LPN [days] }\end{array}$ & 3.1 & 5.3 & $<0.05$ \\
\hline
\end{tabular}

${ }^{1} R B U-$ red blood cell units 
group 2 when compared to group 1 , and it was 5.3 days and 3.1 days respectively. The data are presented in Table III.

\section{Discussion}

Oncological results of LPN are comparable to those of open partial nephrectomy [6]. These data have been confirmed by many authors, who showed that the 5-year survival rate after LPN was similar to that of open surgery [11, 12]. Studies comparing longterm metastasis-free survival between laparoscopic and open kidney tumour resection did not reveal any significant differences [13, 14]. Also results regarding the risk of local recurrence after LPN are not inferior to those of open surgery $[15,16]$. Although this study was not focused on long-term oncological results, according to Lin et al. [13] and Rozanec et al. [15] we consider the low rate of positive surgical margins as a good prognostic factor for recurrence-free survival. Currently most published papers focus on technical aspects, which are supposed to make this procedure less challenging and easier to use for many urologists in a wide group of patients. One of the most important technical problems described by many authors was the necessity for a bloodless operative field. The first way to establish it was clamping the renal pedicle. Kaouk and Gill [17] duplicated laparoscopically the standard open kidney tumourectomy with renal vessel clamping and cold resection of the tumour, repairing the injured collecting system and performing a haemostatic suture of the kidney defect. Other authors successfully performed laparoscopic partial nephrectomy with selective kidney ischaemia through clamping the renal parenchyma around the tumour with a Satynski or Nussbaum clamp $[18,19]$. New techniques facilitating the feasibility of kidney tumour resection without clamping renal vessels have been described. These techniques comprise the use of ultrasonic shears, a diode laser, a water-jet dissector, and microwave coagulation for haemostasis of renal parenchyma [20-23]. Guillonneau et al. compared intra- and postoperative results of LPN done with and without warm ischaemia and concluded that clamping the renal pedicle is associated with less blood loss and shorter operative time [8]. Our outcomes differ from the aforementioned results because our idea about the use of warm ischaemia in this study were different. Our aim was to start every LPN without closing renal vessels and we used pedicle clamping only in case of difficulties with clear tumour resection or performing haemostasis. It was possible due to former dissection of renal vessels and their preparation for immediate clamping if necessary. We managed to complete the surgery with open renal vessels in $34 \%$ of patients, which confirms the feasibility of this method. Other authors also suggest that in selected patients with peripherally located lesions direct excision is feasible without the use of warm ischaemia [5]. The limitation of our study is that it is non-randomized. Patients were allocated to groups based on applied operative technique. Furthermore, the choice of warm ischaemia was influenced by intraoperative course. Therefore more frequent intraoperative complications in group 2 are quite obvious. An important observation in our study is that the LPN done without warm ischaemia is not associated with higher frequency of postoperative complications and that clamping the renal pedicle indeed carries a risk of renal function deterioration. As suggested by many authors $[5,10]$ we attempted not to exceed $30 \mathrm{~min}$ of warm ischaemia time. Despite that, in group 2 we observed more frequent and higher creatinine level elevation. In general, due to the fact that in every case we tried to perform LPN without clamping renal vessels we did not observe increased frequency of postoperative complications in the whole group. Among 38 operated patients in 2 cases (5.2\%) haemorrhage occurred and in 1 patient (2.6\%) urine fistula required reoperation. Similar data were presented by Gill, who reported the frequency of postoperative serious bleeding and prolonged urinary leakage as $4.2 \%$ and $3.1 \%$ of patients respectively [6]. It was also confirmed by Nogueira, who reported these complications in $2.9 \%$ and $2.9 \%$ of cases respectively [24]. In this study we noted better functional outcomes in terms of renal sufficiency among patients operated on without warm ischaemia, which is consistent with the results presented by Thompson et al. [25], indicating that indeed every minute of renal warm ischaemia time really matters.

\section{Conclusions}

We believe that bleeding from cut renal parenchyma after tumour excision, which requires renal pedicle clamping, is an important factor worsening the intra- and postoperative course in patients undergoing laparoscopic kidney tumourectomy. In our opinion laparoscopic resection of kidney tumour 
without warm ischaemia is feasible in pre- and intraoperatively selected cases. The use of non-clamping technique also significantly improves the postoperative course of patients who underwent LPN.

\section{Acknowledgments}

This study has been supported by 2011 scientific funds for research projects of the Pomeranian Medical University (MB-104-26/11).

\section{References}

1. Chłosta P, Drewa T, Obarzanowski M, et al. Do we need a cosmetics effect for radical nephrectomy? Laparoendoscopic singlesite surgery would help to answer this question. Videosurgery Miniinv 2011; 6: 1-4.

2. Otto M, Dzwonkowski J, Grzela T, et al. Laparoscopic nephrectomy - technique and intraoperative kidney localization [Polish] Videosurgery Miniinv 2006; 2: 65-9.

3. Arruabarrena A, Azagra JS, Wilmart JF, et al. Unusual complication after laparoscopic left nephrectomy for renal tumour: a case report. Videosurgery Miniinv 2010; 5: 60-4.

4. Ljungberg B, Cowan N, Hanbury DC, et al. Guidelines on renal cell carcinoma. In: European Association of Urology Guidelines. Arnhem 2010; 25-36.

5. Janetschek G. Laparoscopic partial nephrectomy for RCC: how can we avoid ischemic damage of the renal parenchyma? Eur Urol 2007; 52: 1303-5.

6. Gill IS, Matin SF, Desai MM, et al. Comparative analysis of laparoscopic versus open partial nephrectomy for renal tumors in 200 patients. J Urol 2003; 170: 64-8.

7. Rosales A, Salvador J, De Graeve N, et al. Clamping of renal artery in laparoscopic partial nephrectomy: an old device for a new technique. Eur Urol 2005; 47: 98-101.

8. Guillonneau B, Bermudez H, Gholami S, et al. Laparoscopic partial nephrectomy for renal tumor: single center experience comparing clamping and no clamping techniques of the renal vasculature. J Urol 2003; 169: 483-6.

9. Simon J, Bartsch G, Finter F, et al. Laparoscopic partial nephrectomy with selective control of the renal parenchyma: initial experience with a novel laparoscopic clamp. BJU Int 2008; 103: 805-8.

10. Marberger M. Renal ischaemia: not a problem in laparoscopic partial nephrectomy? BJU Int 2007; 99: 3-4.

11. Lane BR, Gill IS. 5-year outcomes of laparoscopic partial nephrectomy. J Urol 2007; 177: 70-4.

12. Permpongkosol S, Bagga HS, Romero FR, et al. Laparoscopic versus open partial nephrectomy for the treatment of pathological T1NOMO Renal cell carcinoma: a 5-year survival rate. J Urol 2006; 176: 1984-8.

13. Lin YS, Chung HU, Lin AT et al. Laparoscopic partial nephrectomy: Taipei veterans general hospital experience. J Chin Med Assoc 2010; 73: 364-8.

14. Lane BR, Gill IS. 7-year oncological outcomes after laparoscopic and open partial nephrectomy. J Urol 2010; 183: 473-9.
15. Rozanec JJ, Ameri C, Holst P et al. Nephron-sparing surgery: our experience in open and laparoscopic approach in 254 cases. Arch Esp Urol 2010; 63: 62-9.

16. Marszalek M, Meixi H, Polajnar M, et al. Laparoscopic and open partial nephrectomy: a matched-pair comparison of 200 patients. Eur Urol 2009; 55: 1171-8.

17. Kaouk JH, Gill IS. Laparoscopic partial nephrectomy: a new horizon. Curr Opin Urol 2003; 16: 635-43.

18. Verhoest G, Manunta A, Bensalah K, et al. Laparoscopic partial nephrectomy with clamping of the renal parenchyma: initial experience. Eur Urol 2007; 52: 1340-6.

19. Simon J, De Petriconi R, Rinnab L, et al. Optimizing selective renal clamping in nephron-sparing surgery using the Nussbaum clamp. Urology 2008; 22: 22

20. Harmon WJ, Kavoussi LR, Bishoff JT. Laparoscopic nephron-sparing surgery for solid renal masses using the ultrasonic shears. Urology 2000; 56: 754-9.

21. Moinzadeh A, Hasan W, Spaliviero M, et al. Water jet assisted laparoscopic partial nephrectomy without hilar clamping in the calf model. J Urol 2005; 174: 317-21.

22. Ogan K, Jacomides L, Saboorian H, et al. Sutureless laparoscopic heminephrectomy using laser tissue soldering. J Endourol 2003; 17: 295-300

23. Terai A, Ito N, Yoshimura K, et al. Laparoscopic partial nephrectomy using microwave tissue coagulator for small renal tumors: usefulness and complications. Eur Urol 2004; 45: 744-8.

24. Nogueira L, Katz D, Pinochet R, et al. Comparison of gelatin matrix-thrombin sealants used during laparoscopic partial nephrectomy. BJU International 2008; 102: 1670-4.

25. Thompson RH, Lane BR, Lohse CM, et al. Every minute counts when the renal hilum is clamped during partial nephrectomy. Eur Urol 2010; 58: 340-5.

Received: 13.12.2011, Revised: 20.03.2012, Accepted: 5.04.2012. 